\title{
Evaluating the Outcomes of Transactional Analysis and Integrative Counselling Psychology within UK Primary Care Settings
}

\author{
(c) 2011 Biljana van Rijn, Ciara Wild, Patricia Moran
}

\begin{abstract}
The paper reports on a naturalistic study that replicated the evaluative design associated with the UK National Health Service initiative IAPT - Improving Access to Psychological Therapies (CSIP 2008, NHS 2011), as previously used to assess Cognitive Behavioural Therapy (CBT), with the aim of evaluating 12-session treatments for anxiety and depression, applying Transactional Analysis and Integrative Counselling Psychology approaches within real clinical settings in primary care. Standard outcome measures were used in line with the IAPT model (CORE 10 and 34, GAD-7, $P H Q-9)$, supplemented with measurement of the working alliance (WAI Horvath 1986) and an additional depression inventory BDI-II (Beck, 1996), and adherence to the therapeutic model using newly designed questionnaires. Results indicated that severity of problems was reduced using either approach, comparative to Cognitive Behavioural Therapy; that initial severity was predictive of outcome; and that working alliance increased as therapy progressed but was not directly related to outcomes. Adherence was high for both approaches. Several areas for enhancements to future research are suggested.
\end{abstract}

\section{Key words}

Transactional analysis psychotherapy, integrative counselling psychology, CORE, WAI, BDI-11, PHQ-9, GAD7, anxiety/depression, IAPT, CBT.

\section{Introduction}

The research, which took place between 2008 and 2010, with 78 clients and nine therapists, was a product of collaboration between Metanoia Institute in London and the local Primary Care Trust (PCT) in the London
Borough of Ealing. The PCT funded the project to provide and research the effectiveness of short-term Transactional Analysis (TA) and Integrative Counselling Psychology (ICP) psychotherapy in the surgeries of General Practitioners (GPs).

PCTs are those parts of the UK National Health Service (NHS) that are responsible for the local commissioning and provision of services in the first line of health care. The national context was that the UK National Institute for Health and Clinical Excellence (NICE) had issued Guidelines (still in effect) that Cognitive Behavioural Therapy (CBT) was to be the main treatment of choice for anxiety and depression. CBT was, and is, therefore, offered on a large scale within the NHS, including as part of the overall NHS initiative for Improving Access to Psychological Therapies (IAPT) (NHS, 2011).

The PCT, which already provided generic counselling in primary care, wanted to evaluate humanistic and integrative approaches within this health setting in order to make the case for offering wider therapeutic approaches within the NHS and not be limited to CBT. In order to meet that objective the project replicated the methods used within the IAPT initiative (Clark et al, 2009; CSIP, 2008).

Metanoia Institute is a TA psychotherapy training institute which also offers training in ICP and other humanistic approaches. Metanoia Counselling and Psychotherapy Service (MCPS) is the clinical service within the institute that provides low cost treatment to the public and placements for students at Metanoia Institute. MCPS has been engaged in routine clinical evaluation using CORE (CORE Information Management Systems Ltd.) for over ten years. 


\section{Literature Review}

Previous Research

GP surgeries within the UK are significant in the provision of psychological treatments and the first point of contact for clients within the NHS. GP interventions include general medical care, medication, psychological intervention or a combination of these approaches, as well as referrals for medical, surgical and psychological treatments. Previous research studies have compared:

- usual GP care and counselling with effects of medication. Bedi et al (2000) found that both counselling and antidepressants were equally effective and that this was not related to patient preference. Rowland, Bower, Mellor-Clark, Heywood and Hardy (2000) conducted a systematic review of research evidence for the effectiveness of counselling in primary care and found that patients who received counselling, rather than just the usual GP care, demonstrated an improvement in symptoms coupled with a high degree of patient satisfaction.

- effects of medication and psychological therapies. (Bower, Rowland \& Hardy, 2003) conducted a systematic review and meta-analysis of counselling and primary care. They found that brief counselling demonstrated significant short-term improvements in mental health and concluded that it would be a useful addition to mental health services.

- Different psychological therapies, primarily CBT, psychodynamic and interpersonal or person centred. In addition to other 'common factors' research, studies by Mellor-Clark, Connell, Barkham and Cummins (2001), Stiles, Barkham, Mellor-Clark and Connell (2008) and Stiles, Barkham, Twigg, Mellor-Clark and Cooper (2006), conducted in naturalistic settings, found that different orientations were similar in effectiveness, although there were differences in effectiveness of individual therapists.

Even though research is available on both TA and integrative approaches, these approaches have not been subject to systematic evaluation in primary care settings. In the UK this is becoming particularly important in the context of national policies, where clinical guidelines used in the health service do not recommend these treatments.

Transactional Analysis and Integrative Counselling Psychology

TA, from its introduction during the 1960s by Eric Berne (Berne, 1961) has been developed, practised and taught within different professional and national contexts and evaluated in different therapeutic settings (Novey, 1999; Thunnissen, Duivenvoorden \& Trijsburg, 2001; Ohlsson, 2002).
Integrative Counselling Psychology

ICP as taught at Metanoia Institute is rooted in the movement for psychotherapy integration and based on the findings of the 'common factors' research (Orlinsky, Grawe, \& Parks, 1994; Lambert \& Ogles, 2004; Wampold, 2001). Counselling Psychology theory at Metanoia Institute focuses on building integrative frameworks for the therapeutic process, drawing on relational psychoanalysis, systemic, humanistic and existential views of the person.

\section{Research Methodologies}

Evaluative research raises questions about the type of evaluation appropriate in each clinical setting, and whether it will be based on efficacy or effectiveness research design. Effectiveness research is based on clinical practice and takes place in clinical settings, but often suffers from incomplete data and inadequate monitoring of the therapists' approach. Efficacy research design is highly structured, takes place in a laboratory setting, clients and therapists are carefully chosen and the work is closely supervised. This type of research has a high degree of internal validity, but clinicians often find it hard to relate it to the realities of therapeutic practice.

Nathan, Stuart and Dolan (2000) cite the efforts to bridge the gap between the two research designs by developing effectiveness/efficacy clinics which combine features of both. This has been attempted by the National Institute of Mental Health in the US and under the IAPT initiative (Clark et al, 2009) within the UK and this project uses the same approach to evaluation.

\section{Aims}

The aim of the project was to replicate the IAPT approach in order to explore whether TA and ICP psychotherapy, when applied in the same type of setting (GP surgeries), with similar patient groups and the same duration of treatment, would result in similar outcomes to those reported for CBT.

Additional measures were introduced to allow analysis of adherence to the model, working alliances and sessional outcomes.

\section{Ethical Considerations}

Ethical approval for the project was given by Metanoia Institute Research Committee, an independent academic body, approved by Middlesex University.

All clients were given information about the project and signed consent forms. 


\section{Research Design and Participants}

The project was a naturalistic quantitative evaluation, which was designed to replicate the IAPT (CSIP, 2008; Clark et al, 2009) approach to evaluation. As such, it explored treatment outcomes and impact within the 'real world' of clinical practice: specifically it consisted of evaluating the effectiveness of 12-week TA and ICP therapy provided within four allocated GP surgeries.

There were no experimental or control groups, clients were referred through normal channels and were not specifically selected for the research, and there were no researcher hypotheses to prove or reject. Unlike most efficacy research, the therapists were not expected to follow a manual.

\section{Clients}

All clients received a routine GP assessment and were referred as suitable for counselling. They were randomly assigned to TA or ICP. 78 were referred and seen for assessment, 75 attended their first treatment session, $61(78.2 \%)$ were seen for more than six sessions and $17(21.8 \%)$ were seen for fewer than six sessions.

Treatment was defined as the assessment session plus at least one treatment session.

The client group had a wide age range (20 to 88 years). Approximately $74 \%$ of clients were female and $38 \%$ from minority ethnic backgrounds. $36 \%$ of the clients were unemployed and only $19 \%$ were in full time employment. At assessment $77.25 \%$ of clients were above the clinical cut off for anxiety and depression, and $45.16 \%$ were above the clinical cut off on CORE 34 .

\section{Therapists}

Therapists were senior students in the third or fourth years of their training for MSc Transactional Analysis Psychotherapy or a Doctorate in Counselling Psychology that incorporates Integrative Psychotherapy. All had volunteered to take part in the project.

\section{Assessors}

Clinical supervisors who assessed the adherence to the theoretical approach were independent senior practitioners who had ongoing supervisory relationships with the students and were accustomed to using the learning outcomes outlined in the questionnaires, albeit in a different format.

These supervisors had an assessment role at Metanoia Institute, but were not expected to assess quality of practice, which was evaluated quantitatively. Their role included offering help to therapists if they were struggling to maintain adherence to the model.

\section{Research Measures Used}

Table 1 sets out the various measures used and at which sessions.

Table 1: Measures used per session

\begin{tabular}{|c|c|c|c|c|}
\hline & $\begin{array}{c}\text { Every } \\
\text { session }\end{array}$ & $\begin{array}{c}1 \text { st } \\
\text { session }\end{array}$ & $\begin{array}{c}\text { 6th } \\
\text { session }\end{array}$ & $\begin{array}{c}\text { 12th } \\
\text { session }\end{array}$ \\
\hline BDI-11 & & $x$ & $x$ & $x$ \\
\hline CORE 10 & $x$ & $x$ & & \\
\hline CORE 34 & & $x$ & $x$ & $x$ \\
\hline GAD-7 & $x$ & $x$ & & \\
\hline PHQ-9 & $x$ & $x$ & & \\
\hline WAI & $\begin{array}{l}\text { From } \\
\text { 2nd } \\
\text { session }\end{array}$ & & & \\
\hline
\end{tabular}

1st session (Assessment)

At the first session each client was assessed using a battery of standard assessment measures: CORE 34, BDI-II, PHQ-9, GAD-7 and CORE 10, as described and referenced below. In addition to that, the assessment focused on establishing motivation and aims for treatment.

\section{Sessional measures: post each session}

\section{Sessional measures were:}

- Client Health Questionnaire or PHQ-9 (Kroenke, Spitzer \& Williams, 2001): 9-item questionnaire which distinguishes between clinical and non clinical populations;

- General Anxiety Measure, GAD-7 (Spitzer, Kroenke, Williams \& Lowe, 2006): 7-item questionnaire which was initially developed for the Generalised Anxiety Disorder and found to have sensitivity for other anxiety disorders (Kroenke, Spitzer, Williams, Monahan \& Lowe, 2007);

- CORE 10 (CORE Information Management Systems Ltd, 2007): 10-item questionnaire focusing on categories of well being, functioning, problems/ symptoms and risk.

- Working Alliance Inventory, WAI (Horvath, 1986): 12-item questionnaire developed to measure working alliance as defined by Bordin (1979) used from the second session. 
Pre, mid and post therapy measures:

Additional measures used at the first, sixth and the twelfth session were:

- BDI-II (Beck, 1996): 21-item questionnaire measuring depression

- CORE 34 (Barkham et al, 2001): 34-item questionnaire focusing on categories of well being, functioning, problems/symptoms and risk and distinguishing between clinical and non clinical populations.

The mid therapy measures aimed to collect data about the flow of therapy and increase the percentage of full data sets where the clients did not complete the full treatment.

\section{Adherence to the model}

Adherence questionnaires were designed based on the core skills, theoretical knowledge and attitudes taught within each course, as defined in course handbooks and externally validated by Middlesex University and the national umbrella bodies of UK Council for Psychotherapy (UKCP), British Association for Counselling and Psychotherapy (BACP) and the British Psychological Society (BPS). Adherence was measured using a 5-point scale, across 16 items for TA and 24 items for ICP. Details are given in the Appendix. The ratings were done on the basis of student presentations and three audio recordings of sessions for each client. Audio recordings were familiar to therapists and supervisors as part of normal supervisory practice.

\section{Results}

Outcomes are presented in the format which broadly follows the evaluation by Clark et al (2009), for ease of comparison. An overall data set, with comparisons between the TA and ICP groups, is followed by the statistics related to each outcome measure. Finally, there is statistical analysis of associations between measures.

\section{Data set}

78 clients referred for therapy attended the assessment session; 38 were allocated to TA therapists and 40 to $\mathrm{CPI}$ therapists. Independent t-test found no significant differences in pre therapy scores on CORE 34 and BDI11 between the two groups. 75 clients attended the first treatment session. Of these, $17(21.8 \%)$ attended fewer than six sessions and $61(78.2 \%)$ attended more than six sessions. The average number of sessions attended was nine, and $60 \%$ of all endings were planned.

As shown in Table 2, the sessional measures had a high percentage of completeness (97\%) and allowed the analysis of outcomes at the end of therapy, even where the 'pre and post' measures were missing. The level of data completeness for CORE 34 was lower at $70.5 \%$ and $\mathrm{BDI}-\mathrm{II}$ at $73.1 \%$.
Table 2: Participants and data completeness

\begin{tabular}{|c|c|c|c|c|}
\hline Measure & $\begin{array}{l}\text { Number } \\
\text { complete }\end{array}$ & $\begin{array}{l}\text { Number } \\
\text { incomplete }\end{array}$ & $\begin{array}{c}\% \\
\text { complete }\end{array}$ & $\begin{array}{c}\% \\
\text { incomplete }\end{array}$ \\
\hline Complete & 48 & - & 61.5 & - \\
\hline Ended & 30 & - & - & 38.5 \\
\hline $\begin{array}{c}\text { BDI-II } \\
\text { Mid/Post* }\end{array}$ & 57 & 21 & 73.1 & 26.9 \\
\hline $\begin{array}{l}\text { CORE-34 } \\
\text { Mid/Post }^{*}\end{array}$ & 55 & 23 & 70.5 & 29.5 \\
\hline PHQ-9 & 74 & 3 & 97 & 3 \\
\hline GAD-7 & 74 & 3 & 97 & 3 \\
\hline CORE-10 & 74 & 3 & 97 & 3 \\
\hline WAI & 74 & 3 & 97 & 3 \\
\hline $\begin{array}{c}6 \\
\text { Sessions } \\
+/-\end{array}$ & 61 & $17^{* *}$ & 78.2 & $21.8^{* *}$ \\
\hline
\end{tabular}

Note. ${ }^{*}$ Calculated using only clients who have completed up to session 6 or are ongoing and therefore have a mid therapy measure (if this was their last measure before they ended sessions this is also counted as their Post or final measure).

${ }^{*}$ * Less than six sessions completed.

\section{Treatment outcomes: CORE 34 and BDI-11}

Table 3 shows the means for CORE 34 and BDI-11 at the three points in time. Results of a paired t-test used to investigate the differences between pre, mid and post scores showed that significant differences existed at $\mathrm{P}<$ 0.05 between scores for the pre-post $(t=4.341) \mathrm{BDI}-\mathrm{II}$ and mid-post BDI $(\mathrm{t}=4.524)$, mid-post $(\mathrm{t}=4.606)$ and pre-post $(t=4.418)$ Core 34 totals, mid-post $(t=3.064)$ and mid-post $(\mathrm{t}=-3.744)$ and pre-post $(\mathrm{t}=-3.261)$.

Due to unplanned endings there was a smaller number of clients (55-57\%) who completed these measures before and at the end of therapy. IAPT guidelines (Clark, 2009) indicate completeness of $6 \%$ at their Doncaster site and $56 \%$ in the Newham site for the Core 34 outcome measure.

Table 3: BDI-Il and CORE 34 Descriptive Statistics

\begin{tabular}{lccc}
\hline Measure & Number & Mean & $\begin{array}{c}\text { Std. } \\
\text { deviation }\end{array}$ \\
\hline Pre therapy BDI & 78 & 28.7 & 13.3 \\
Mid therapy BDI & 57 & 27.2 & 13.7 \\
Post therapy BDI & 45 & 18.8 & 13.6 \\
Pre CORE & 77 & 62.5 & 24.6 \\
Mid CORE & 54 & 60.4 & 24.6 \\
Post CORE & 42 & 45.2 & 23.4 \\
\hline
\end{tabular}




\section{Treatment outcomes: sessional measures}

Descriptive statistics for the sessional measures are shown in Table 4. A paired t-test showed a significant difference at $\mathrm{P}<0.05$ between scores for pre-post $\mathrm{PHQ}$ $9(\mathrm{t}=3.233)$, pre-post GAD-7 $(\mathrm{t}=4.842)$, mid-post CORE $10(t=3.064)$ and pre-post CORE $10(t=3.877)$.

The high percentage of completed data sets for final session outcomes, at $97 \%$, is well above the IAPT guideline of $80 \%$ (D.M. Clark et al, 2009).

Table 5 shows the improvement status for client from the first assessment to the end of therapy. Therapy is defined as a minimum of an assessment plus one session.

Overall, mean scores decreased towards the end of therapy but not in a linear direction. The standard deviation of scores increased and decreased across sessions and between participants showing periods of greater variation. This suggested that some clients became more distressed before getting better.

To ascertain further the meaning of outcomes, severity of the problems was analysed for all clients at the beginning and the end of therapy. The percentage of clients recorded as non clinical across the sessional measures was $43.36 \%$ (between $33.3 \%$ and $49.4 \%$ ) reduced from $77.25 \%$ at the start of therapy. Non clinical was defined using the same parameters as the IAPT report (Clark et al, 2009) where scores of nine or over on the PHQ-9 are considered clinical and scores of seven or over on the GAD-7 are considered clinical. Scores of ten or above on the CORE 10 are considered clinical following the Core 10 manual.

The average percentage of clients who have improved using sessional measures was $57.7 \%$ (between $55.1 \%$ and $64.1 \%)$.

\section{Working Alliance Inventory (WAI)}

The working alliance was regarded as an essential factor to the effective therapeutic process, as taught within both training programmes and supported by common factors research (Norcross, 2002). Results in Table 6 show that the mean for the working alliance increased as the therapy progressed. A paired t-test showed that there was a significant difference between mid-post $(\mathrm{t}=-3.744)$ and pre-post $(\mathrm{t}=-3.261)$.

\section{Table 6: Working Alliance Inventory descriptive} statistics

\begin{tabular}{|c|c|c|c|c|c|}
\hline & $\mathbf{N}$ & Min & Max & Mean & $\begin{array}{c}\text { Std. } \\
\text { deviation }\end{array}$ \\
\hline $\begin{array}{l}\text { Session } 2 \\
\text { total }\end{array}$ & 51 & 33 & 84 & 60.49 & 12.383 \\
\hline $\begin{array}{l}\text { Session } 6 \\
\text { total }\end{array}$ & 51 & 34 & 84 & 65.92 & 12.818 \\
\hline $\begin{array}{l}\text { Session } 11 \\
\text { total }\end{array}$ & 38 & 38 & 84 & 68.53 & 13.506 \\
\hline
\end{tabular}

Table 4: Sessional measures PDQ-9, GAD-7, CORE 10 descriptive statistics

\begin{tabular}{lcccccccccc}
\hline & \multicolumn{3}{c}{ Pre therapy } & \multicolumn{3}{c}{ Mid therapy } & \multicolumn{3}{c}{ Post therapy } \\
\hline & Mean & SD & N & Mean & SD & N & Mean & SD & N \\
\hline PHQ-9 & 14.1 & 7.3 & 75 & 11.5 & 7.3 & 56 & 8.9 & 6.2 & 39 \\
GAD-7 & 12.7 & 6.2 & 76 & 10.1 & 6.6 & 53 & 8.0 & 5.8 & 39 \\
CORE 10 & 19.5 & 7.8 & 77 & 17.7 & 8.9 & 56 & 13.9 & 8.0 & 37 \\
\hline
\end{tabular}

Table 5: Improvement status PHQ-9, GAD-7 and Core 10

\begin{tabular}{lcccccc}
\hline & \multicolumn{2}{c}{ PHQ-9 } & \multicolumn{2}{c}{ GAD-7 } & \multicolumn{2}{c}{ CORE 10 } \\
\hline N & N & N & $\%$ & N & $\%$ \\
\hline Improve & 44 & 54.5 & 47 & 60.3 & 50 & 64.1 \\
No change & 11 & 14.1 & 16 & 20.5 & 14 & 17.9 \\
Deteriorate & 21 & 26.9 & 15 & 19.2 & 14 & 17.9 \\
No date & 2 & 2.6 & & & & \\
\hline Total & 78 & 100 & 78 & 100 & 78 & 100 \\
\hline
\end{tabular}




\section{Associations between variables}

A Chi Squared was carried out to examine possible associations between variables and showed:

- significant associations $(p<0.01)$ between completion status and improvement on the BDI-11

- significant associations in the completion of more than six sessions and improvement on the BDI-11, PHQ-9, GAD-7 and CORE 34. A regression was employed to ascertain whether client severity at the start of therapy predicted scores at the end of therapy. It was found that first session scores significantly predicted $(P<0.05)$ final session scores on all of the measures.

Repeated ANOVA showed no significant differences between theoretical orientation and improvement on any of the measures, nor between individual therapists and improvement on any of the measures.

\section{Adherence to the model}

Results for adherence to therapeutic model suggested that practitioners' adherence to their models were similar and high, $86 \%$ adherence for TA and $81 \%$ for ICP psychotherapy.

\section{Discussion}

\section{The Results}

IAPT services within the UK specialise in treatment of anxiety and depression and the IAPT report (Clark et al, 2009) found that on entering the service, approximately $86 \%$ of clients were scoring above the clinical cut off on the depression and anxiety measures being used. Generic primary care counselling, as in this project, receives referrals assessed for a 'lower intensity treatment' (CSIP, 2008) that is not based on individual diagnostic categories. However, $77.25 \%$ of the clients seen in this research project were also classified as above the clinical cut off for anxiety and depression at the start of therapy. These results suggested that depression and anxiety were more widespread in clinical populations and supports (Drozd \& Goldfried, 1996) critique that single diagnostic categories may not be the best basis for evaluation or signposting for treatments.

Treatment outcomes showed that TA and ICP psychotherapy achieved change for an average of $57.7 \%$ of the clients referred, comparable to the IAPT demonstration sites (Clark et al, 2009) using CBT, which showed a change for $55 \%$ clients who have attended at least twice. Although the figures were limited by a small sample, the high percentage of full data sets for sessional measures suggested robustness in comparison to IAPT evaluation. Clark, Fairburn \& Wessely (2008) and Clark et al (2009) demonstrated data completeness for sessional measures of $88.3 \%$ and $99.6 \%$ in their two demonstration sites, in comparison to $97 \%$ within this research project. IAPT data completeness for CORE 34 was $6 \%$ and $56 \%$ in the two demonstration sites. Data completeness for CORE-34 in this research project of $70.3 \%$ was far higher.

These results showed that brief TA and ICP psychotherapy were comparable in their effectiveness to CBT within a primary care setting, when measured in a similar way.

Completing a number of questionnaires each session may have had an impact on the outcomes. Lambert et al (2002) and Miller, Duncan, Brown, Sorrel and Chalk (2006) found that clients used evaluation measures as one of the ways to give feedback to the therapist on their experiences. This feedback improved outcomes, such as achievement of reliable change and better attendance. Follow up information might clarify whether the gains were maintained in the longer term, but this was not available in this setting.

\section{The Therapists and the Orientation}

There were no differences shown in effectiveness between the therapists or the orientations even though the therapists showed a high level of adherence to treatment models. This was expected on the basis of the common factors research (Smith \& Glass, 1977; Asay \& Lambert, 1999; Wampold, 2001; Lambert \& Ogles, 2004) and the Dodo bird effect (Rozenweig, 1936).

However, the expectations of difference in the performance of individual therapists (Mellor-Clark, Connell, Barkham, \& Cummins, 2001; M. J. Lambert \& Ogles, 2004) was not met. The therapists worked with similar clients and numbers and all performed to a steady level. This may have been related to the similarity in their training background or to being coached by supervisors within the same training environment, where the different approaches share the same overall philosophy. Outcomes could be different within different training establishments.

The adherence questionnaires were experienced as long and sometimes cumbersome by both therapists and supervisors. They are a new measure, which needs to be developed further and standardised.

Using supervisors as assessors was experienced as helpful by the practitioners as it became part of the supervision process and offered structure and focus. However, despite their professional role and assessment experience, existing relationships with supervisors might have led to bias. The impact of the coaching was also not quantified. For greater fidelity, use of research supervisors, or random checks of recordings by the researchers, could be recommended for future projects, with and without accompanying coaching. 


\section{The Working Alliance}

Working alliance outcomes showed that the alliance increased within the duration of therapy. Therapists found the measure useful to attend to potential ruptures in the relationship, but there was no evidence that the strength of the working alliance predicted the outcomes, even though it was expected that this would be a factor (Horvath \& Bedi, 2002). However, clients who stayed in therapy longer had better outcomes, so the strength of the working alliance may have had an impact on the clients' ability to use therapy.

It may be, of course that completing the WAI had an impact on the therapy itself.

\section{Methodology}

The research team was able to use the IAPT (CISP 2008) methodology to evaluate the effectiveness of treatments in real clinical settings and achieve sufficient data completeness to enable them to reach their conclusions.

For a more complete evaluation, baseline measurements prior to assessment and follow up measures would have been useful: it would have been particularly useful to evaluate whether clients were able to maintain their gains at the end of therapy.

Measuring the adherence to the theoretical model was another area for development. These new measures need to be tested in future projects, developed and standardised.

\section{Future Developments}

The outcomes of this research point to the need to conduct further studies with larger samples. This setting did not allow for an extension of the length of therapy according to the needs of the client, or for a follow up. The outcomes showed that severity of the scores at the outset predicted severity at the end. This suggested that longer treatment may be more appropriate for clients with more severe difficulties. To address this Metanoia Institute has applied this research clinic model to its internal service, where a larger scale project started in September 2010. The new project allows for a larger sample, longer treatments, an opportunity of a follow up and comparisons between several theoretical approaches.

Dr Biljana van Rijn Teaching and Supervising Transactional Analyst (Psychotherapy) and the Head of Clinical Studies at Metanoia Institute. She can be contacted on Biljana.vanRijn@metanoia.ac.uk

Ciara Wild MSc Forensic Psychology is Researcher/ Clinic Administrator at Metanoia Institute.

Dr Patricia Moran Chartered Psychologist in the Integrative Department at Metanoia Institute, London, where she tutors on the Doctorate in Counselling Psychology and Psychotherapy by Professional Studies

\section{References}

Asay, T. P. \& Lambert, M. J. (1999). The Empirical Case for the Common Factors in Therapy:quantitative findings. In M. Hubble, B. Duncan, L. \& S. D. Miller (Eds.), The Heart and Soul of Change:What Works in Therapy, 531-537. Washington,D.C: American Psychological Association.

Barkham, M., Margison, F., Leach, C., Lucock, M., J., M.-C. \& Evans, C. (2001). Service Profiling and Outcomes Benchmarking Using the CORE-OM: Toward PracticeBased Evidence in the Psychological Therapies. Journal of Consulting and Clinical Psychology, 69, 184-196.

Beck, A. (1996). United States of America Patent No. 0154018392

Bedi, N., Chivlers, C., Churchill, R., Dewey, M., Duggan, C., Fielding, K. et al (2000). Assessing effectiveness of treatment of depression in primary care: Partially randomised preference trial. British Journal of Psychiatry, October 2000 (177), 312-318.

Bordin, E. S. (1979). The Generalizability of the Psychoanalytic Concept of the Working Alliance. Psychotherapy: Theory, Research, Practice, 16 (3), 252-260.

Bower, P., Rowland, N. \& Hardy, G. (2003). The clinical effectiveness of counselling in primary care: a systematic review and meta-analysis. Psychological Medicine, 33 (2), 203-215.

Clark, D. M., Layard, R., Smithies, R., Richards, D. A., Suckling, R., \& Wright, B. (2009). Improving access to psychological therapy: Initial evaluation of two demonstration sites. Behaviour Research and Therapy, 47, 910-920.

CORE Information Management Systems Ltd. Outcome Measure 34. from http://www.coreims.co.uk accessed 29/7/11.

CORE Information Management Systems Ltd. (2007). CORE Net. from http://www.coreims-online.co.uk accessed 29/7/11.

CSIP. (2008). Improving Access to Psychological Therapies (IAPT) Commissioning Toolkit. http://ebookbrowse.com/iapt-commissioning-toolkit-pdfd48273738 accessed 27/07/11

Drozd, J. F. \& Goldfried, M. R. (1996). A Critical Evaluation Of The State-Of-The-Art In Psychotherapy Outcome Research. Psychotherapy: Theory, Research, Practice, Training, 33 (2), 171-180.

Horvath, A. O. (1986). Another Approach to Assess the Counselling Relationship:The Working Alliance. Paper presented at the American Educational Research Association.

Horvath, A. O. \& Bedi, R. P. (2002). The Alliance. In J. C Norcross (Ed.), Psychotherapy Relationships That Work. Therapist Contributions and Responsiveness to Patients, 37-69. New York: Oxford University Press. 
Kroenke, K., Spitzer, R. L., \& Williams, J. B. (2001). The PHQ9: Validity of a Brief Depression Severity Measure. Journal of General and Internal Medicine, 16, 606-613.

Kroenke, K., Spitzer, R. L., Williams, J., Monahan, P. O. \& Lowe, B. (2007). Anxiety Disorders in Primary Care: Prevalence, Impairment, Comorbidity, and Detection. Annals of Internal Medicine, 146, 317-325.

Lambert, M. J., Whipple, J. L., Vermeersch, D. A. D., Smart, W., Hawkins, E. J., Nielsen, S. L. et al (2002). Enhancing Psychotherapy Outcomes via Providing Feedback on Client Progress: a Replication. Clinical Psychology \& Psychotherapy, 9 (2), 91-103.

Lambert, M. J. \& Ogles, B. M. (2004). The Efficacy and Effectiveness of Psychotherapy. In M. J. Lambert (Ed.), Bergin and Garfield's Handbook of Psychotherapy and Behaviour Change (5th ed.). New York: Wiley.

Mellor-Clark, J., Connell, J., Barkham, M. \& Cummins, P. (2001). Counselling Outcomes in Primary Health Care: a CORE System Data Profile. European Journal of Psychotherapy \& Counselling, 4 (1), 65-86.

Nathan, P. E., Stuart, S. P. \& Dolan, S. L. (2000). Research on Psychotherapy Efficacy and Effectiveness: Between Scylla and Charybdis? Psychological Bulletin, 126 (6), 964-981.

NHS (2011) http://www.iapt.nhs.uk/about-iapt/ accessed 22/7/2011.
Rowland, N., Bower, P., Mellor-Clark, J., Heywood, P. \& Hardy, R. (2000). Counselling in Primary Care: a Systematic Review of the Research Evidence. British Journal of Guidance \& Counselling, 28 (2), 215-231.

Smith, M. L. \& Glass, G. V. (1977). Meta-Analysis of Psychotherapy Outcome Studies. American Psychologist, 32 (9), 752-760.

Spitzer, R. L., Kroenke, R., Williams, J. B. \& Lowe, B. (2006). A Brief Measure for Assessing Generalized Anxiety Disorder: the GAD-7. Archives of Internal Medicine, 166, 1092-1097.

Stiles, W. B., Barkham, M., Twigg, E., Mellor-Clark, J. \& Cooper, M. (2006). Effectiveness of Cognitive Behavioural, Person-Centred and Psychodynamic Therapies as Practised in the UK National Health Service Settings. Psychological Medicine, 36, 555-566.

Stiles, W. B., Barkham, M. Mellor-Clark, J., \& Connell, J. (2008). Effectiveness of Cognitive-Behavioural, PersonCentred, and Psychodynamic Therapies in UK PrimaryCare Routine Practice: Replication in a Larger Sample. Psychological Medicine, 38 (5), 677-688.

Wampold, B. (2001). The Great Psychotherapy Debate. New Jersey: Lawrence Erlbaum Associates. 


\section{APPENDIX A: Adherence Questionnaires:}

Both questionnaires carried the following instructions:

This form should be completed every four weeks for each client using a segment of tape from the client's sessions.

Please complete this form by placing a cross in the box beside the number that you feel best represents the extent to which the practitioner adheres to each aspect of the model for Transactional Analysis. For this scale, the number 1 represents 'no adherence' and the number 5 represents 'Fully adhered', for example: -

Capacity to initiate, develop and maintain an effective therapeutic alliance, based on principles of respect and equality (I'm OK You're OK)

$\begin{array}{ccrrr}\text { No } & \text { Little } & \text { Partly } & \text { Mostly } & \text { Fully } \\ \text { adherence } & \text { adherence } & \text { adhered } & \text { adhered } & \text { adhered } \\ 1 & 2 & 3 & 4 & 5\end{array}$

Transactional Analysis Adherence Questionnaire

Section 1- Working Alliance, diagnosis, contracting and treatment planning and interventions

1. Capacity to initiate, develop and maintain an effective therapeutic alliance, based on principles of respect and equality (I'm OK You're OK)

2. Capacity to make an appropriate clinical assessment using Transactional Analysis theory

3. Capacity to make an appropriate clinical assessment using Core, DSM and/or where appropriate other diagnostic systems

4. Capacity to develop therapeutic contracts which take account of the needs and context of the client

5. Capacity to devise treatment plans based on Transactional Analysis models of treatment planning

6. Capacity to use the Therapeutic Operations to effect decontamination

7. Capacity to engage effectively with the co-transferential relationship as a means of effecting deconfusion

\section{Section 2 - Theoretical Understanding and Reflection}

8. Capacity to describe and reflect upon clinical interventions using Transactional Analysis e.g. Game's analysis, Script analysis, TA proper, Ego state exploration, etc

9. Capacity to reflect on the effectiveness of interventions given the stage of treatment and the clinical content

10. Capacity to explain interventions using a variety of TA approaches

11. Can explain chosen interventions in response to an evolving sense of a personal style

12. Awareness of and capacity to reflect on own counter-transferential process and its meaning for the work

Section 3 - Working ethically, professionally and safely

13. Ability to work with issues of difference and pay attention to psychosocial, cultural and contextual factors as appropriate

14. Ability to engage in and effect risk assessments and address issues of safety as appropriate

15. Pays attention to ethical and professional issues and demonstrates ability to work with these

16. Uses appropriate professional support for the ongoing development of thinking and practice 
Integrative Counselling Psychology Adherence Questionnaire

1. Ability to conduct appropriate psychological assessments based on good inter-personal capabilities and a broad understanding of mental health

2. Ability to initiate, develop and maintain an effective therapeutic alliance

3. Demonstration of an understanding of psychopathology and diagnostic systems

4. A clear conceptualisation of treatment planning, goals and relevant change processes

5. Demonstration of the ability to contract with the client on therapeutic goals, activities and outcomes

6. Understanding of relationship dynamics at multiple levels of exchange

7. Demonstration of knowledge of theories of development throughout the lifespan

9. The capacity to integrate in a coherent way theories and competencies from more than one tradition in the psychological therapies

10. A capacity to attend to explicit and implicit communications and an ability to work with these

11. Sensitivity to attunement/misattunements

12. The ability to work with an understanding of the self in its multiple facets

13. Awareness of and capacity to reflect on own counter-transferential process and its meaning for the work

14. Understanding of the co-created nature of the therapeutic exchange

15. Effective and creative use of the self of the therapist

16. Ability to respond to complex demands as required

17. A capacity to attend to psychosocial, cultural and contextual factors as appropriate

18. Ability to work with issues of difference

19. A capacity to work towards self understanding in the client and an increase of awareness in the client of options for change

20. The ability to reflect on the appropriateness of interventions in line with stage of treatment, clinical content and client feedback

21. Engagement in risk assessment and attention to safety as appropriate

22. The capacity to attend to ethical and professional issues and the ability to work with these the use of appropriate professional support for the ongoing development of thinking and practice

23. The ability to monitor and evaluate therapeutic practice

24. A capacity to manage endings in the therapeutic process 